\title{
Nutrição e produtividade do amendoim em sucessão ao cultivo de plantas de cobertura no sistema plantio direto
}

\author{
Carlos Alexandre Costa Crusciol(1) e Rogério Peres Soratto ${ }^{(1)}$
}

\author{
(1)Universidade Estadual Paulista, Fac. de Ciências Agronômicas, Campus de Botucatu, Caixa Postal 237, CEP $18603-970$ Botucatu, SP. \\ E-mail: crusciol@fca.unesp.br, soratto@fca.unesp.br
}

\begin{abstract}
Resumo - O objetivo deste trabalho foi avaliar a produção de matéria seca e o acúmulo de nutrientes por plantas de cobertura e o efeito do manejo da palhada na nutrição e produtividade do amendoim da seca, em sucessão, no sistema plantio direto. O experimento foi instalado em um Latossolo Vermelho distroférrico, em Botucatu, SP. $\mathrm{O}$ delineamento utilizado foi o de blocos ao acaso, em parcelas subdivididas, com quatro repetições. As parcelas foram constituídas por três espécies de plantas de cobertura: braquiária - Brachiaria brizantha, cultivar Marandu; milheto - Pennisetum glaucum, cultivar BN 2; e panicum - Panicum maximum, cultivar Mombaça. As subparcelas foram constituídas pela ausência e presença do manejo mecânico da palhada, 20 dias após o manejo químico, mediante o uso de triturador de palha horizontal. O milheto apresentou a maior produção de matéria seca e o menor teor de nutrientes na parte aérea, aos 71 dias após a emergência, em comparação com a braquiária e o panicum. As quantidades de nutrientes acumuladas na parte aérea das plantas de cobertura foram semelhantes. A espécie de planta de cobertura do solo e o manejo mecânico da palhada não influenciam a nutrição e a produtividade do amendoim no sistema plantio direto.
\end{abstract}

Termos para indexação: Arachis hypogaea, Brachiaria brizantha, Pennisetum glaucum, Panicum maximum, manejo mecânico, componentes da produção.

\section{Peanut crop nutrition and yield in no-tillage system in succession to cover crops growth}

\begin{abstract}
The objective of this work was to evaluate cover crops shoot dry matter production and nutrients accumulation and the effect of straw mulch mechanical management on the dry season peanut crop nutrition and yield, in no-tillage system. The experiment was carried out on a dystroferric Hapludox, in Botucatu, SP, Brazil. A randomized blocks design, in a splitplot array, with four replications, was used. The plots were composed by cover crops: palisadegrass - Brachiaria brizantha cv. Marandu; pearl millet - Pennisetum glaucum cv. BN 2; and guineagrass - Panicum maximum cv. Mombaça. The subplots were composed by absence or presence of straw mulch mechanical management, by horizontal crusher use, 20 days after chemical management. Pearl millet presented the largest shoot dry matter production and the lowest nutrient contents, 71 days after emergence, in comparison with palisadegrass and guineagrass. The cover crops presented similar nutrients accumulation in shoot. The cover crops species and straw mulch mechanical management does not affect the peanut leaves nutrient contents and yield in no-tillage system.

Index terms: Arachis hypogaea, Brachiaria brizantha, Pennisetum glaucum, Panicum maximum, mechanical management, yield components.
\end{abstract}

\section{Introdução}

O sistema plantio direto promove inúmeros benefícios ao solo, tais como: maior proteção contra o impacto direto das gotas de chuva, favorecimento da infiltração, redução da perda de água por escoamento superficial e da perda de solo e nutrientes por erosão (Hermani et al., 1999). Além disso, propicia maior disponibilidade de água e nutrientes às plantas e melhora as condições físicas e químicas do solo, com o aumento da matéria orgânica. Na safra de 2005/2006, foram cultivados 25,5 milhões de hectares sob esse sistema (Federação Brasileira de Plantio Direto na Palha, 2007), o que corresponde a mais de 50\% da área cultivada com culturas produtoras de grãos.

Atualmente, os centros de pesquisa têm dado grande ênfase à adaptação de culturas ao sistema plantio direto, 
com vistas ao aumento no número de opções disponíveis para compor os esquemas de rotação, prática que se constitui em um dos pilares para o sucesso desse sistema de manejo do solo.

O cultivo do amendoim no Brasil ocupa aproximadamente 129.500 ha. Cerca de $75 \%$ da produção nacional está concentrada no Estado de São Paulo (Companhia Nacional de Abastecimento, 2007). Essa produção, em sua quase totalidade, advém de áreas de reforma de canaviais, nas quais o amendoim é a principal cultura utilizada na rotação com a cana-deaçúcar. Recentemente, em razão da legislação, as empresas canavieiras paulistas têm que reduzir gradativamente as queimadas de canaviais; conseqüentemente, ocorre aumento do uso de máquinas colhedoras de cana crua, que deixam sobre a superfície do solo, após a colheita, aproximadamente $15 \mathrm{Mg} \mathrm{ha}^{-1}$ de matéria seca, que formam uma camada de palha de 8 a $10 \mathrm{~cm}$ de espessura (Bolonhezi et al., 2007).

Uma outra utilização da cultura do amendoim é a rotação com pastagens, na integração lavoura-pecuária, na Região Oeste do Estado de São Paulo, com objetivo de reforma de pastagens degradadas, mas com condições de solo favoráveis à semeadura de culturas graníferas diretamente sobre a palhada remanescente das forrageiras, sem necessidade de prévio preparo do solo.

Nas regiões Sudeste e Centro-Oeste do Brasil, grande parte da área cultivada com pastagens é ocupada por gramíneas dos gêneros Brachiaria e Panicum (Landers, 2007). Além dessas, segundo Pitol (1999), outra gramínea bastante cultivada é o milheto (Pennisetum glaucum (L.) R. Brown).

Segundo Borkert et al. (2003), as palhadas de gramíneas são fornecedoras de nutrientes às culturas sucessoras. Braz et al. (2004) verificaram que o milheto, a braquiária e o panicum têm capacidade de acumular grande quantidade de nutrientes. Contudo, são relativamente recentes os estudos acerca da influência dos resíduos culturais deixados na superfície do solo sobre a produtividade de culturas cultivadas em sucessão e, praticamente inexistentes, no que se refere à cultura do amendoim. Além disso, os resultados são inconsistentes. Carvalho et al. (2004a, 2004b) não observaram efeito da cultura de cobertura antecessora na produtividade de algodão e milho. Silveira et al. (2005) verificaram maior produtividade de feijão de inverno, em sucessão ao milheto, em comparação à braquiária e ao panicum. Nunes et al. (2006) não verificam diferença na produtividade do feijoeiro, em plantio direto sobre palhada de braquiária e panicum.

O tipo de manejo pode influenciar a decomposição da palhada e, conseqüentemente, a liberação de nutrientes para a cultura em sucessão (Argenta et al., 2001). Porém, o uso de implementos específicos para o manejo da palhada, como o triturador de palha horizontal, pode acarretar desvantagens como baixo rendimento operacional, alto custo (Reis et al., 2007) e risco de compactação do solo. Contudo, pouco se sabe sobre o efeito do tipo de manejo da palhada sobre o desempenho da cultura do amendoim, em sucessão.

No Brasil, trabalhos quanto à viabilidade da implantação da cultura do amendoim, em sistema plantio direto ou em preparos conservacionistas, são quase inexistentes. Resultados indicam que o desenvolvimento dessa tecnologia possibilitará o cultivo do amendoim no sistema plantio direto, em áreas de colheita de cana crua (Bolonhezi et al., 2007), reforma de pastagens e em rotação com culturas graníferas, o que proporcionará maior sustentabilidade na produção do amendoim. Além disso, a adoção do arrancamento e a inversão das plantas, de forma totalmente mecanizada, e a utilização de trilhadoras equipadas com distribuidor de palha podem tornar o amendoim uma alternativa para rotação no sistema plantio direto ou para uso em áreas de reforma de pastagens, nas quais não haja necessidade de preparo convencional do solo.

O objetivo deste trabalho foi avaliar a produção de matéria seca e o acúmulo de nutrientes por plantas de cobertura, e o efeito do manejo mecânico da palhada na nutrição e na produtividade do amendoim da seca, no sistema plantio direto.

\section{Material e Métodos}

O experimento foi conduzido na Fazenda Experimental Lageado, da Faculdade de Ciências Agronômicas, da Universidade Estadual Paulista, Município de Botucatu, SP $\left(22^{\circ} 58^{\prime} \mathrm{S}\right.$ e $48^{\circ} 23^{\prime} \mathrm{W}$ e $765 \mathrm{~m}$ de altitude). O solo do local é um Latossolo Vermelho distroférrico (Embrapa, 1999), manejado há dois anos no sistema plantio direto (2001/2002 -milho/crotalária; 2002/2003 - milheto/aveia-preta).

As características químicas e granulométricas do solo $(0-20 \mathrm{~cm})$ foram determinadas antes da instalação do experimento, e os resultados foram: $26,1 \mathrm{~g} \mathrm{dm}^{-3}$ matéria orgânica; $\mathrm{pH}\left(\mathrm{CaCl}_{2}\right) 5,2 ; 12,1 \mathrm{mg} \mathrm{dm}^{-3}$ de $\mathrm{P}$ (resina); $1,2,22,2,8,8$ e $32,1 \mathrm{mmol}_{\mathrm{c}} \mathrm{dm}^{-3}$ de $\mathrm{K}, \mathrm{Ca}, \mathrm{Mg}$ e H+Al, 
respectivamente; $11,0 \mathrm{mg} \mathrm{dm}^{-3}$ de $\mathrm{S}^{-\mathrm{SO}_{4}}{ }^{2-}$; e $50 \%$ de saturação por bases. Os teores de areia, silte e argila foram $637,61,5$ e $301,5 \mathrm{~g} \mathrm{~kg}^{-1}$, respectivamente. As precipitações pluviais e temperaturas máximas e mínimas registradas, durante a condução do experimento, são apresentadas na Figura 1.

O delineamento experimental utilizado foi o de blocos ao acaso, em esquema de parcelas subdivididas, com quatro repetições. As parcelas foram constituídas por três espécies de plantas de cobertura: braquiária Brachiaria brizantha (Hochst. ex A. Rich.) Stapf., cultivar Marandu; milheto - Pennisetum glaucum (L.) R. Brown, cultivar BN 2; e panicum - Panicum maximum Jacq., cultivar Mombaça. As subparcelas foram constituídas pela ausência ou presença do manejo mecânico da palhada, mediante o uso de triturador de palha horizontal, 20 dias após o manejo químico. Cada subparcela teve $5 \mathrm{~m}$ de largura e $10 \mathrm{~m}$ de comprimento.

Antes da semeadura das plantas de cobertura, foi realizada a dessecação das plantas presentes na área, mediante a aplicação do herbicida glifosato $\left(1.920 \mathrm{~g} \mathrm{ha}^{-1}\right.$ de i.a.). As espécies de cobertura foram semeadas no dia $7 / 11 / 2003$, no espaçamento de $0,17 \mathrm{~m}$ entre as linhas, com 20,15 e $18 \mathrm{~kg} \mathrm{ha}^{-1}$ de sementes de braquiária, milheto e panicum, respectivamente. A emergência das plantas ocorreu no dia 19/11/2003.

No dia 29/1/2004, 71 dias após a emergência (DAE) das plantas de cobertura, foi realizada a coleta da parte aérea, para determinação da produção de massa de matéria seca e teor de nutrientes. Foram coletadas, aleatoriamente, por subparcela, duas subamostras de $0,25 \mathrm{~m}^{2}$ da parte aérea das plantas, para formar uma

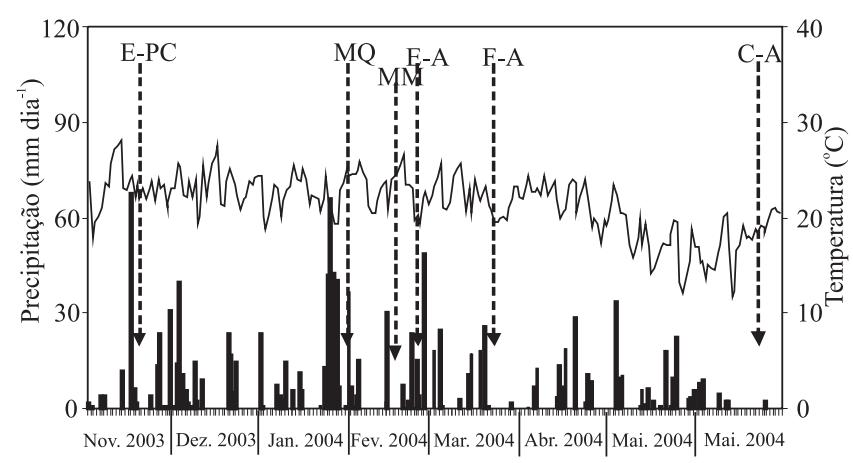

Figura 1. Precipitação pluvial (I) e temperatura média (-), obtidas na área experimental durante o período de novembro de 2003 a junho de 2004. E-PC: emergência das plantas de cobertura; MQ: manejo químico das plantas de cobertura; MM: manejo mecânico da palhada; E-A: emergência do amendoim; F-A: início do florescimento do amendoim; C-A: colheita do amendoim. única amostra. No total, foram tomadas oito amostras compostas, por espécie, antes da aplicação dos tratamentos de manejo. O material coletado foi secado em estufa a $65^{\circ} \mathrm{C}$ e, em seguida, foram realizadas a pesagem e a transformação dos dados em $\mathrm{kg} \mathrm{ha}^{-1}$ de matéria seca. Posteriormente, realizou-se a moagem do material colhido para determinação dos teores dos macronutrientes ( $\mathrm{N}, \mathrm{P}, \mathrm{K}, \mathrm{Ca}, \mathrm{Mg}$ e $\mathrm{S})$, segundo Malavolta et al. (1997). De posse dos resultados de massa de matéria seca e teores de nutrientes, foram calculadas as quantidades acumuladas por hectare. Na mesma data de coleta das amostras, foi realizado o manejo químico, por meio da aplicação de glifosato (3.600 $\mathrm{g} \mathrm{ha}^{-1}$ do i.a.), com volume de calda de $250 \mathrm{~L} \mathrm{ha}^{-1}$. No momento do manejo químico, o milheto encontrava-se no estádio de grãos leitosos, e as demais espécies no estádio de alongamento de entrenós (fase vegetativa).

Em metade de cada parcela, foi realizado o manejo mecânico da palhada 20 dias após o manejo químico, com auxílio de triturador de palha horizontal mecanizado. $\mathrm{Na}$ mesma data, foi realizada a semeadura do amendoim, com a cultivar IAC Tatu Vermelho, no espaçamento de 0,45 m entre linhas e 18 sementes por metro de linha. A adubação básica nos sulcos de semeadura foi de $200 \mathrm{~kg} \mathrm{ha}^{-1}$ da fórmula 8-28-16. A emergência das plantas ocorreu no dia 25/2/2004. O florescimento do amendoim ocorreu no dia 19/3/2004.

O controle das plantas daninhas foi realizado mediante a aplicação do herbicida fluazifop-p-butil (70 $\mathrm{g} \mathrm{ha}^{-1}$ do i.a.), no dia $9 / 3 / 2004$, e bentazone ( $890 \mathrm{~g} \mathrm{ha}^{-1}$ do i.a.), no dia 16/3/2004.

Para o controle de pragas, principalmente trips (Enneothrips flavens e Caliothrips brasiliensis), foram realizadas as pulverizações com os inseticidas metamidofós (300 $\mathrm{g} \mathrm{ha}^{-1}$ do i.a.) nos dias 9/3/2004 e 16/3/2004 e cloropirifós (400 $\mathrm{g} \mathrm{ha}^{-1}$ do i.a.) no dia 1\%/4/2004. Para o controle de doenças, principalmente cercosporioses (Cercosporidium personatum e Cercospora arachidicola), foram realizadas pulverizações com o fungicida tebuconazole $\left(150 \mathrm{~g} \mathrm{ha}^{-1}\right.$ do i.a.) nos dias $1 \% / 4,23 / 4,14 / 5$ e $2 / 6$ de 2004 . A colheita do amendoim foi realizada no dia 22/6/2004.

Por ocasião do florescimento pleno do amendoim, foram amostradas 40 plantas por subparcela (tufo apical do ramo principal) (Ambrosano et al., 1996). O material foi secado em estufa a $65^{\circ} \mathrm{C}$, até peso constante. Em seguida as plantas foram moídas para posterior determinação dos teores de $\mathrm{N}, \mathrm{P}, \mathrm{K}, \mathrm{Ca}, \mathrm{Mg}$ e $\mathrm{S}$ (Malavolta et al., 1997). 
Por ocasião da colheita do amendoim, foram determinados os componentes da produção (população final de plantas, número de vagens granadas por planta, número de grãos por vagem e massa de 100 grãos), a produtividade de vagens e o rendimento de grãos.

Para a determinação da produtividade de vagens, foram colhidas, manualmente, as plantas contidas em três linhas de $6 \mathrm{~m}$ de comprimento na área útil de cada subparcela. Após a trilha manual e a limpeza do material, com separação das impurezas (torrões, folhas e ramos), as vagens foram pesadas e, posteriormente, foi calculada a produtividade de vagens em $\mathrm{kg} \mathrm{ha}^{-1}$ (9\% de umidade). $\mathrm{O}$ rendimento de grãos foi determinado, em cada subparcela, mediante a relação peso de grãos/peso de vagens, em porcentagem.

Os dados obtidos para a cultura do amendoim foram submetidos à análise de variância, e as médias foram comparadas por meio do teste t (DMS), a 5\% de probabilidade.

\section{Resultados e Discussão}

A produtividade de massa de matéria seca variou entre as espécies de plantas de cobertura do solo (Tabela 1). $\mathrm{O}$ milheto se destacou com produtividade média de $8.909 \mathrm{~kg} \mathrm{ha}^{-1}$. Produtividade semelhante de matéria seca do milheto foi observada por Carvalho et al. (2004a, 2004b), com semeadura da cultivar Comum, em outubro, e manejo aos 60 DAE. Contudo, Oliveira et al. (2002), com semeadura em novembro da mesma cultivar e manejo aos 100 DAE, Braz et al. (2004), com semeadura em dezembro da cultivar BN 2 e avaliação aos 52 DAE, e Boer et al. (2007), com a cultivar ADR 500 e manejo aos 51 DAE, observaram produtividades superiores. O panicum apresentou produtividade de matéria seca intermediária $\left(6.886 \mathrm{~kg} \mathrm{ha}^{-1}\right)$, superior à da braquiária (6.267 kg ha-1), valores próximos aos verificados para essas culturas por Nunes et al. (2006), em Diamantina (MG), com as mesmas cultivares, porém, em um período de crescimento bem mais longo do que o do presente trabalho.

Para todas as espécies, a produtividade de matéria seca foi superior a $6.000 \mathrm{~kg} \mathrm{ha}^{-1}$, citada por Darolt (1998) como a quantidade mínima ideal de adição de matéria seca em um sistema de rotação de culturas, para que se mantenha adequada cobertura do solo. A quantidade de palha sobre o solo e a uniformidade de sua distribuição podem servir de referência para uma avaliação preliminar sobre as condições em que o sistema plantio direto está se desenvolvendo (Alvarenga et al., 2001). A elevada produção de matéria seca das plantas de cobertura esteve relacionada à época de cultivo, já que durante o ciclo dessas plantas ocorreu boa precipitação (Figura 1).

Quanto ao teor de nutrientes na parte aérea das plantas de cobertura, observou-se que, de maneira geral, o milheto apresentou menores teores que as demais espécies, com exceção dos teores de $\mathrm{P}, \mathrm{Ca}$ e $\mathrm{Mg}$ observados no panicum, do teor de $\mathrm{K}$ na braquiária e do teor de S, que foi semelhante para todas as espécies. Os menores teores de nutriente no milheto podem estar relacionados ao efeito de diluição, já que o milheto produziu maior quantidade de matéria seca (Tabela 1), ou ao estádio fenológico das plantas, pois, no momento do manejo, o milheto se encontrava no estádio de grãos leitosos, e as demais espécies na fase vegetativa. Boer et al. (2007) verificaram, em milheto semeado em abril na região do cerrado de Goiás, e manejado no florescimento pleno (51 DAE), teores de $\mathrm{Ne} \mathrm{S}$ menores, de $\mathrm{K}$ e $\mathrm{Ca}$ maiores e de $\mathrm{Mg}$ e $\mathrm{P}$ semelhantes aos observados no presente trabalho. Segundo Braz et al. (2004), o milheto apresenta acúmulo máximo de nutrientes no limbo foliar aos 52-55 DAE, com posterior queda nos valores, e a braquiária e o panicum apresentam aumento nos teores até épocas posteriores.

Tabela 1. Matéria seca, teores e quantidade acumulada de macronutrientes na parte aérea das plantas de cobertura. Médias de oito repetições ${ }^{(1)}$.

\begin{tabular}{|c|c|c|c|c|c|c|c|c|c|c|c|c|c|}
\hline \multirow[t]{2}{*}{ Tratamento } & \multirow{2}{*}{$\begin{array}{l}\text { Matéria seca } \\
\left(\mathrm{kg} \mathrm{ha}^{-1}\right)\end{array}$} & \multicolumn{6}{|c|}{ Teor na parte aérea $\left(\mathrm{g} \mathrm{kg}^{-1}\right)$} & \multicolumn{6}{|c|}{ Quantidade acumulada na parte aérea $\left(\mathrm{kg} \mathrm{ha}^{-1}\right)$} \\
\hline & & $\mathrm{N}$ & $\mathrm{P}$ & $\mathrm{K}$ & $\mathrm{Ca}$ & $\mathrm{Mg}$ & $\mathrm{S}$ & $\mathrm{N}$ & $\mathrm{P}$ & $\mathrm{K}$ & $\mathrm{Ca}$ & $\mathrm{Mg}$ & $\mathrm{S}$ \\
\hline Braquiária & $6.267 \mathrm{c}$ & $18,5 \mathrm{a}$ & $2,1 \mathrm{a}$ & $18,9 \mathrm{ab}$ & $6,6 \mathrm{a}$ & $4,6 \mathrm{a}$ & $3,7 \mathrm{a}$ & $116,8 \mathrm{a}$ & $13,3 \mathrm{a}$ & $117,4 \mathrm{a}$ & $41,5 \mathrm{ab}$ & $29,0 \mathrm{a}$ & $23,3 b$ \\
\hline Milheto & $8.909 \mathrm{a}$ & $13,3 b$ & $1,5 b$ & $13,9 \mathrm{~b}$ & $5,2 b$ & $3,2 b$ & $3,6 \mathrm{a}$ & $118,2 \mathrm{a}$ & $13,5 \mathrm{a}$ & $120,2 \mathrm{a}$ & $46,3 a$ & $28,5 \mathrm{ab}$ & $31,8 \mathrm{a}$ \\
\hline Panicum & $6.886 \mathrm{~b}$ & $18,4 \mathrm{a}$ & $1,6 \mathrm{ab}$ & $20,7 \mathrm{a}$ & $5,4 \mathrm{~b}$ & $3,4 \mathrm{~b}$ & $3,5 \mathrm{a}$ & $126,8 \mathrm{a}$ & $13,3 \mathrm{a}$ & $142,8 \mathrm{a}$ & $37,1 \mathrm{~b}$ & $23,0 \mathrm{~b}$ & $23,7 \mathrm{~b}$ \\
\hline CV (\%) & 7,1 & 17,6 & 29,1 & 29,1 & 11,6 & 17,8 & 17,3 & 19,8 & 28,7 & 29,2 & 12,8 & 18,6 & 17,4 \\
\hline
\end{tabular}

(1)Médias seguidas por letras iguais, na coluna, não diferem entre si pelo teste t (DMS), a 5\% de probabilidade. 
Para os nutrientes N, P e K, verificou-se que não houve diferença entre as espécies, em relação à quantidade acumulada (Tabela 1). Assim, mesmo tendo apresentado maiores teores, a braquiária e o panicum não apresentaram maiores acúmulos desses nutrientes, em razão da menor produção de matéria seca. Segundo Boer et al. (2007), mesmo tendo produzido maior quantidade de matéria seca, o milheto não acumulou maiores quantidades de N, P, Ca, $\mathrm{Mg}$ e $\mathrm{S}$ do que o capim pé-de-galinha (Eleusine coracana (L.) Gaertn.). Para Braz et al. (2004), o milheto apresenta maior velocidade de acumulação de matéria seca e nutrientes no limbo foliar do que a braquiária e o panicum, com o máximo acúmulo entre 52 e 55 DAE. Esses autores verificaram que o máximo acúmulo de $\mathrm{N}, \mathrm{P}$ e K pelo milheto foi de 348, 36 e $341 \mathrm{~kg} \mathrm{ha}^{-1}$, respectivamente, para uma produção de matéria seca de $12.553 \mathrm{~kg} \mathrm{ha}^{-1}$, valores superiores aos observados neste trabalho, o que pode estar relacionado à fertilidade do solo, à adubação utilizada, ao estádio fenológico em que foi realizada a avaliação e à parte da planta avaliada, já que mensuraram o acúmulo de nutrientes apenas no limbo foliar das culturas, enquanto neste trabalho foi considerada toda a parte aérea das plantas.

$\mathrm{O}$ milheto apresentou maior acúmulo de $\mathrm{Ca}$ (46,3 $\mathrm{kg} \mathrm{ha}^{-1}$ ), seguido da braquiária e do panicum. Quanto ao $\mathrm{Mg}$, houve destaque da braquiária, que apresentou o maior teor desse elemento, porém, estatisticamente semelhante ao do milheto (Tabela 1). Com relação ao acúmulo de $\mathrm{S}$, verificou-se a superioridade do milheto, em consequiência da maior produção de matéria seca, já que o teor desse nutriente foi semelhante em todas as espécies estudadas. Oliveira et al. (2002) e Braz et al. (2004) trabalharam com várias culturas de cobertura e relataram que o milheto foi a cultura que teve o maior acúmulo e ciclagem de macronutrientes. Entre outras características, o milheto se destaca por seu sistema radicular profundo e alta capacidade de extração de nutrientes (Pitol, 1999).

No que diz respeito à cultura do amendoim, os fatores estudados não afetaram o desenvolvimento das plantas; em todos os tratamentos, foi observada produção de matéria seca semelhante (Tabela 2).

Os fatores não afetaram os teores de nutrientes nas folhas do amendoim (Tabela 2). Em todos os tratamentos, os teores de $\mathrm{N}, \mathrm{P}$ e $\mathrm{Mg}$ nas folhas do amendoim estavam na faixa considerada adequada para a cultura (Gascho \& Davis, 1995; Ambrosano et al., 1996), enquanto os de K estavam abaixo. Com relação ao teor de $\mathrm{Ca}$, apesar de não ter havido diferença estatística entre os tratamentos, os teores do nutriente, onde anteriormente foi cultivado panicum ou onde não houve manejo mecânico das plantas de cobertura, encontravam-se na faixa de $12-20 \mathrm{~g} \mathrm{~kg}^{-1}$, considerada adequada por Gascho \& Davis (1995) e Ambrosano et al. (1996). Porém, nos demais tratamentos, os teores foram inferiores a esse intervalo. Os teores de $\mathrm{S}$, em todos os tratamentos, estavam acima da faixa adequada (Gascho \& Davis, 1995; Ambrosano et al., 1996), em razão dos elevados teores desse elemento no solo.

Tabela 2. Matéria seca da parte aérea e teores de macronutrientes nas folhas do amendoim, cultivado no sistema plantio direto sobre palhada de diferentes plantas de cobertura, com e sem manejo mecânico da palhada ${ }^{(1)}$.

\begin{tabular}{|c|c|c|c|c|c|c|c|}
\hline \multirow[t]{2}{*}{ Tratamento } & \multirow{2}{*}{$\begin{array}{c}\text { Matéria seca } \\
\left(\mathrm{g}_{\text {planta }}^{-1}\right)\end{array}$} & \multicolumn{6}{|c|}{ Teor nas folhas $\left(\mathrm{g} \mathrm{kg}^{-1}\right)$} \\
\hline & & $\mathrm{N}$ & $\mathrm{P}$ & $\mathrm{K}$ & $\mathrm{Ca}$ & $\mathrm{Mg}$ & $\mathrm{S}$ \\
\hline \multicolumn{8}{|c|}{ Planta de cobertura } \\
\hline Braquiária & $11,4 \mathrm{a}$ & $37,3 \mathrm{a}$ & $2,1 \mathrm{a}$ & $13,9 \mathrm{a}$ & $10,4 a$ & $4,1 \mathrm{a}$ & $9,8 \mathrm{a}$ \\
\hline Milheto & $11,6 \mathrm{a}$ & $38,8 \mathrm{a}$ & $3,2 \mathrm{a}$ & $14,1 \mathrm{a}$ & $11,8 \mathrm{a}$ & $4,8 \mathrm{a}$ & $11,2 \mathrm{a}$ \\
\hline Panicum & $10,6 \mathrm{a}$ & $34,0 \mathrm{a}$ & $3,6 \mathrm{a}$ & $13,3 \mathrm{a}$ & $13,9 \mathrm{a}$ & $4,1 \mathrm{a}$ & $10,3 \mathrm{a}$ \\
\hline CV (\%) & 32,6 & 9,6 & 48,5 & 24,9 & 23,8 & 30,2 & 11,5 \\
\hline \multicolumn{8}{|c|}{ Manejo mecânico } \\
\hline Sem & $12,3 a$ & $36,4 a$ & $2,9 \mathrm{a}$ & $13,7 \mathrm{a}$ & $12,2 \mathrm{a}$ & $4,0 \mathrm{a}$ & $10,4 \mathrm{a}$ \\
\hline Com & $10,1 \mathrm{a}$ & $37,0 \mathrm{a}$ & $3,0 \mathrm{a}$ & $13,8 \mathrm{a}$ & $11,0 \mathrm{a}$ & $4,7 \mathrm{a}$ & $10,4 \mathrm{a}$ \\
\hline $\mathrm{CV}(\%)$ & 23,8 & 6,2 & 46,4 & 20,9 & 16,7 & 17,0 & 11,7 \\
\hline
\end{tabular}

${ }^{(1)}$ Médias seguidas por letras iguais, na coluna, dentro de cada fator, não diferem entre si pelo teste t (DMS), a 5\% de probabilidade. 
Os componentes da produção, a produtividade e o rendimento não foram afetados pelos fatores estudados (Tabela 3). Bolonhezi et al. (2005) relatam produção de grãos de amendoim, no sistema plantio direto sobre palhada de cana-de-açúcar, $30 \%$ superior ao sistema convencional, mesmo com redução na população final de plantas, provavelmente em conseqüência da atenuação dos efeitos da deficiência hídrica, proporcionada pela manutenção de palha na superfície do solo. Segundo esses autores, resultados preliminares indicavam viabilidade do plantio direto do amendoim, em sucessão ao milheto e à braquiária. Com relação ao cultivo de outras leguminosas em sistema plantio direto, para Oliveira et al. (2002), a palhada do milheto foi a que proporcionou maior produtividade de feijão cultivado em sucessão. Nunes et al. (2006) verificaram maior produtividade do feijão no sistema plantio direto sobre palhada de braquiária (Brachiaria brizantha cv. Marandu) e panicum (Panicum maximum cv. Mombaça), em comparação com outras gramíneas e leguminosas.

A produtividade de vagens atingida pode ser considerada satisfatória, em se tratando de cultivo da seca (semeadura em 18/2) em sistema plantio direto, pois Quaggio \& Godoy (1996) consideraram, para o Estado de São Paulo, três classes de produtividade para o amendoim em sistema convencional: baixa - menor que $1.500 \mathrm{~kg} \mathrm{ha}^{-1}$; média - entre 1.500 e $3.000 \mathrm{~kg} \mathrm{ha}^{-1}$; e alta - maior que $3.000 \mathrm{~kg} \mathrm{ha}^{-1}$. Ao trabalhar com essa mesma cultivar, em sistema plantio direto sobre palhada de cana crua, Tasso Junior (2003) obteve $2.000 \mathrm{~kg} \mathrm{ha}^{-1}$ de vagens, em condições climáticas mais favoráveis para a cultura, uma vez que realizou a semeadura em 14/11/1999.

Os resultados de produtividade de vagens obtidos neste trabalho corroboram os obtidos por Crusciol et al. (2000, 2003) e Lazarini \& Crusciol (2000), em condições de cultivo da seca. Esses autores obtiveram produtividades, na região de Selvíria (MS), em época de semeadura semelhante à adotada no presente estudo, que variaram de 1.600 a $2.200 \mathrm{~kg} \mathrm{ha}^{-1}$. Bolonhezi et al. (2005) relataram produtividade de vagens do amendoim da seca, cultivado em plantio direto sobre palhada de cana-de-açúcar, de $1.881 \mathrm{~kg} \mathrm{ha}^{-1}$, valor semelhante ao observado nos sistemas convencional e de cultivo mínimo. É importante ressaltar que, em razão das condições climáticas desfavoráveis (especialmente baixas temperaturas e deficiência hídrica) (Figura 1), houve redução nos valores de alguns componentes da produção, em comparação aos valores obtidos pelos autores supracitados, o que refletiu em menor produtividade. Neste trabalho, verificou-se, em média, 1,8 grão por vagem, massa de 100 grãos de $35,3 \mathrm{~g}$ e rendimento de $62-65 \%$, valores menores do que os observados pelos autores citados.

Considerando-se os resultados obtidos neste trabalho, e as produtividades comumente obtidas na época da seca (Crusciol et al., 2000, 2003; Lazarini \& Crusciol, 2000; Tasso Júnior, 2003; Bolonhezi et al., 2007), é importante destacar a possibilidade de se semear o amendoim em sistema plantio direto, em sucessão às culturas do milheto, braquiária ou panicum, mesmo com grande quantidade de palha na superfície ( $\left.8.900 \mathrm{~kg} \mathrm{ha}^{-1}\right)$, sem que haja prejuízo no estabelecimento e produtividade da cultura.

Tabela 3. Componentes da produção, produtividade e rendimento do amendoim, cultivado no sistema plantio direto sobre palhada de diferentes plantas de cobertura, com e sem manejo mecânico da palhada ${ }^{(1)}$.

\begin{tabular}{|c|c|c|c|c|c|c|}
\hline Tratamento & $\begin{array}{l}\text { População final } \\
\left(\mathrm{pl} . \mathrm{ha}^{-1}\right)\end{array}$ & $\begin{array}{c}\text { № de vagens } \\
\text { granadas por planta }\end{array}$ & $\begin{array}{c}\text { № de grãos } \\
\text { por vagem }\end{array}$ & $\begin{array}{c}\text { Massa de } \\
100 \text { grãos }(\mathrm{g})\end{array}$ & $\begin{array}{c}\text { Produtividade de } \\
\text { vagens }\left(\mathrm{kg} \mathrm{ha}^{-1}\right)\end{array}$ & $\begin{array}{l}\text { Rendimento de } \\
\text { grãos (\%) }\end{array}$ \\
\hline \multicolumn{7}{|c|}{ Planta de cobertura } \\
\hline Braquiária & $344.444 a$ & $5,4 a$ & $1,4 \mathrm{a}$ & $35,9 \mathrm{a}$ & $1.741 \mathrm{a}$ & $62,8 \mathrm{a}$ \\
\hline Milheto & $312.963 \mathrm{a}$ & $7,7 \mathrm{a}$ & $1,6 \mathrm{a}$ & $33,9 a$ & $2.074 \mathrm{a}$ & $65,8 \mathrm{a}$ \\
\hline Panicum & $320.370 \mathrm{a}$ & $6,5 \mathrm{a}$ & $1,6 \mathrm{a}$ & $36,1 \mathrm{a}$ & $1.775 \mathrm{a}$ & $63,8 \mathrm{a}$ \\
\hline $\mathrm{CV}(\%)$ & 22,4 & 41,2 & 16,9 & 5,9 & 16,7 & 4,3 \\
\hline \multicolumn{7}{|c|}{ Manejo mecânico } \\
\hline Sem & $330.864 a$ & $6,2 \mathrm{a}$ & $1,5 \mathrm{a}$ & $35,7 \mathrm{a}$ & $1.865 \mathrm{a}$ & $62,7 \mathrm{a}$ \\
\hline Com & $320.988 \mathrm{a}$ & $6,8 \mathrm{a}$ & $1,5 \mathrm{a}$ & $34,9 \mathrm{a}$ & $1.862 \mathrm{a}$ & $65,6 \mathrm{a}$ \\
\hline CV (\%) & 22,9 & 37,4 & 36,7 & 6,3 & 16,1 & 3,1 \\
\hline
\end{tabular}

${ }^{(1)}$ Médias seguidas por letras iguais, na coluna, dentro de cada fator, não diferem entre si pelo teste t (DMS), a 5\% de probabilidade. 


\section{Conclusões}

1. O milheto apresenta maior produção de massa de matéria seca e menor teor de nutrientes na parte aérea, aos 71 dias após a emergência, em comparação com a braquiária e o panicum.

2. As quantidades de nutrientes acumuladas na parte aérea das diferentes plantas de cobertura são semelhantes.

3. A espécie de planta de cobertura do solo e o manejo mecânico da palhada não influenciam a nutrição e a produtividade do amendoim no sistema plantio direto.

\section{Agradecimentos}

Ao CNPq, por bolsa concedida ao primeiro autor; à Fapesp, pelo financiamento da pesquisa.

\section{Referências}

ALVARENGA, R.C.; LARA CABEZAS, W.A.R.; CRUZ, J.C.; SANTANA, D.P. Plantas de cobertura de solo para sistema plantio direto. Informe Agropecuário, v.22, p.25-36, 2001.

AMBROSANO, J.E.; TANAKA, R.T.; MASCARENHAS, H.A.A.; RAIJ, B. van; QUAGGIO, J.A.; CANTARELLA, H. Leguminosas e oleaginosas. In: RAIJ, B. van; CANTARELLA, H.; QUAGGIO, J.A.; FURLANI, A.M.C. (Ed.). Recomendações de adubação e calagem para o Estado de São Paulo. 2.ed. Campinas: Instituto Agronômico; Fundação IAC, 1996. p.189-203 (Boletim Técnico, 100).

ARGENTA, G.; SILVA, P.R.F. da; FLECK, N.G.; BORTOLINI, C.G.; NEVES, R.; AGOSTINETTO, D. Efeitos do manejo mecânico e químico da aveia-preta no milho em sucessão e no controle do capim-papuã. Pesquisa Agropecuária Brasileira, v.36, p.851-860, 2001.

BOER, C.A.; ASSIS, R.L. de; SILVA, G.P.; BRAZ, A.J.B.P.; BARROSO, A.L. de L.; CARGNELUTTI FILHO, A.; PIRES, F.R. Ciclagem de nutrientes por plantas de cobertura na entressafra em um solo de cerrado. Pesquisa Agropecuária Brasileira, v.42, p.1269-1276, 2007.

BOLONHEZI, D.; GODOY, I.J. de; SANTOS, R.C. dos. Manejo da cultura do amendoim. In: SANTOS, R.C. dos (Ed.). O agronegócio do amendoim no Brasil. Campina Grande: Embrapa Algodão, 2005. p.193-244.

BOLONHEZI, D.; MUTTON, M.A.; MARTINS, A.L.M. Sistemas conservacionistas de manejo do solo para amendoim cultivado em sucessão à cana crua. Pesquisa Agropecuária Brasileira, v.42, p.939-947, 2007.

BORKERT, C.M.; GAUDÊNCIO, C. de A.; PEREIRA, J.E.; PEREIRA, L.R.; OLIVEIRA JÚNIOR, A. de. Nutrientes minerais na biomassa da parte aérea em culturas de cobertura de solo. Pesquisa Agropecuária Brasileira, v.38, p.143-153, 2003.
BRAZ, A.J.B.P.; SILVEIRA, P.M. da; KLIEMANN, H.J.; ZIMMERMANN, F.J.P. Acumulação de nutrientes em folhas de milheto e dos capins braquiária e mombaça. Pesquisa Agropecuária Tropical, v.34, p.83-87, 2004.

CARVALHO, M.A.C. de; ATHAYDE, M.L.F.; SORATTO, R.P.; ALVES, M.C.; SÁ, M.E. de. Adubação verde e sistemas de manejo do solo na produtividade do algodoeiro. Pesquisa Agropecuária Brasileira, v.39, p.1205-1211, 2004a.

CARVALHO, M.A.C. de; SORATTO, R.P.; ATHAYDE, M.L.F.; ARF, O.; SÁ, M.E. de. Produtividade do milho em sucessão a adubos verdes no sistema de plantio direto e convencional. Pesquisa Agropecuária Brasileira, v.39, p.47-53, 2004b.

COMPANHIA NACIONAL DE ABASTECIMENTO (Brasília, DF). Safras 1976/77 a 2006/07: série histórica. Disponível em: http://www.conab.gov.br/safras.asp. Acesso em: 19 abr. 2007.

CRUSCIOL, C.A.C.; LAZARINI, E.; GOLFETO, A.R.; SÁ, M.E. de. Produtividade e componentes da produção do amendoim da seca em razão da época de semeadura e da aplicação de cálcio. Pesquisa Agropecuária Brasileira, v.35, p.1549-1558, 2000.

CRUSCIOL, C.A.C.; LAZARINI, E.; SORATTO, R.P. Efeito da aplicação de calcário no sulco de semeadura sobre a nutrição e produtividade de amendoim semeado em diferentes épocas no cultivo da seca. Científica, v.31, p.201-209, 2003.

DAROLT, M.R. Princípios para implantação e manutenção do sistema. In: DAROLT, M.R. Plantio direto: pequena propriedade sustentável. Londrina: Iapar, 1998. p.16-45.

EMBRAPA. Centro Nacional de Pesquisa de Solos. Sistema brasileiro de classificação dos solos. Rio de Janeiro: EmbrapaCNPS, 1999. 412p.

FEDERAÇÃO BRASILEIRA DE PLANTIO DIRETO NA PALHA (Ponta Grossa, PR). Evolução do plantio direto no Brasil. Disponível em: http://www.febrapdp.org.br. Acesso em: 19 mar. 2007.

GASCHO, G.; DAVIS, J.G. Soil fertility and plant nutrition. In: PATEE, H.E.; STALKER, H.T. (Ed.). Advances in peanut science. Stillwater: American Peanut Research and Education Society, 1995. p.383-419.

HERNANI, L.C.; KURIHARA, C.H.; SILVA, W.M. da. Sistema de manejo do solo e perdas de nutrientes e matéria orgânica por erosão. Revista Brasileira de Ciência do Solo, v.23, p.145-154, 1999.

LANDERS, J.N. Tropical crop-livestock systems in conservation agriculture: the Brazilian experience. Rome: FAO, 2007. 102p. (Integrated Crop Management, 5).

LAZARINI, E.; CRUSCIOL, C.A.C. Produtividade do amendoim da seca em função do sistema de produção e da época de semeadura. Revista de Agricultura, v.75, p.287-301, 2000.

MALAVOLTA, E.; VITTI, G.C.; OLIVEIRA, S.A. de. Avaliação do estado nutricional das plantas: princípios e aplicações. 2.ed. Piracicaba: Potafos, 1997. 308p.

NUNES, U.R.; ANDRADE JÚNIOR, V.C.; SILVA, E. de B.; SANTOS, N.F.; COSTA, H.A.O.; FERREIRA, C.A. Produção de 
palhada de plantas de cobertura e rendimento do feijão em plantio direto. Pesquisa Agropecuária Brasileira, v. 41, p.943-948, 2006. OLIVEIRA, T.K. de; CARVALHO, G.J. de; MORAES, R.N. de S. Plantas de cobertura e seus efeitos sobre o feijoeiro em plantio direto. Pesquisa Agropecuária Brasileira, v.37, p.1079-1087, 2002.

PITOL, C.O. O milheto em sistemas de plantio direto. In: FARIAS NETO, A.L.; AMABILE, R.F.; MARTINS NETO, D.A.; YAMASHITA, T.; GOCHO, H. (Ed.). Worskhop Internacional de Milheto. Planaltina: Embrapa-CPAC, 1999. p.69-73.

QUAGGIO, J.A.; GODOY, I.J. Amendoim. In: RAIJ, B. van; CANTARELlA, H.; QUAGGIO, J.A.; FURLANI, A.M.C. Recomendações de adubação e calagem para o Estado de São Paulo. 2.ed. Campinas: IAC, 1996. p.192 (Boletim Técnico, 100).
REIS, G.N. dos; FURLANI, C.E.A.; SILVA, R.P. da; GERLACH, J.R.; CORTEZ, J.W.; GROTTA, D.C.C. Decomposição de culturas de cobertura no sistema plantio direto, manejadas mecânica e quimicamente. Engenharia Agrícola, v.27, p.194-200, 2007.

SILVEIRA, P.M. da; BRAZ, A.J.B.P.; KLIEMANN, H.J.; ZIMMERMANN, F.J.F. Adubação nitrogenada no feijoeiro cultivado sob plantio direto em sucessão de culturas. Pesquisa Agropecuária Brasileira, v.40, p.377-381. 2005.

TASSO JÚNIOR, L.C. Cultura da soja, milho e amendoim sob diferentes sistemas de manejo do solo em área com palha residual de colheita mecanizada de cana crua. 2003. 154p. Dissertação (Mestrado) - Universidade Estadual Paulista, Jaboticabal.

Recebido em 20 de abril de 2007 e aprovado em 26 de setembro de 2007 